\title{
RESPEITO COMO PRINCÍPIO ÉTICO ESSENCIAL EM PESQUISAS GENÉTICAS E GENÔMICAS
}

\section{ARTIGO ORIGINAL}

TOLEDO, Thiago Ferreira de ${ }^{1}$

TOLEDO, Thiago Ferreira de. Respeito como princípio ético essencial em pesquisas genéticas e genômicas. Revista Científica Multidisciplinar Núcleo do Conhecimento. Ano 05, Ed. 12, Vol. 05, pp. 179-205. Dezembro de 2020. ISSN: 24480959, Link de acesso: https://www.nucleodoconhecimento.com.br/etica/principio-etico

\section{RESUMO}

A genética se ocupa em estudar como as características dos organismos são transmitidas a seus descendentes, e, genômica, por sua vez, estuda a totalidade da informação genética. Nesse contexto, por serem campos de estudos que envolvem diretamente a biologia dos seres vivos, é fundamental a consideração de sólidos princípios éticos para nortear essas pesquisas. Frente a isso, tendo em conta estudos éticos produzidos na República da África do Sul, cujas condições do país o tornam propício para essas investigações, bem como ensinamentos da Ciência Logosófica, este trabalho tem como objetivo propor o princípio ético de respeito a ser considerado como fator essencial em pesquisas envolvendo genética e genômica, por ser esse um princípio que engloba valores que convidam a uma boa convivência, estimulando a encontrar soluções que confluam para a harmonia, porque busca ajustar as diferenças, as necessidades e os interesses entre os indivíduos.

Palavras-chave: Bioética, biotecnologia, ética, ética em pesquisa, logosofia.

\footnotetext{
${ }^{1}$ Mestre em Engenharia Elétrica e Computação
} 


\section{INTRODUÇÃO}

No século XX houve três grandes projetos que abriram novas possibilidades para a humanidade. O Projeto Manhattan descobriu as formas de utilização da energia nuclear, o Projeto Apollo possibilitou a exploração do espaço sideral e o Projeto Genoma Humano, que resultou na ampliação do conhecimento sobre a herança biológica do ser humano (MALUF, 2020).

Como ainda no século XXI as pesquisas relacionadas com o Projeto Genoma Humano continuam sendo desenvolvidas, tal como a edição genética de dois bebês que vieram a nascer em outubro de 2018 (GREELY, 2019), pode-se dizer que os objetivos com esse intento ainda não foram alcançados.

Para contextualizar o que significa esses estudos, a genética se refere a busca do conhecimento da hereditariedade, com o intuito de descobrir como as características dos organismos são transmitidas para as próximas gerações, por meio do ADN (ácido desoxirribonucleico; ou, em língua inglesa, DNA - deoxyribonucleic acid). Já a pesquisa genômica lida com a totalidade da informação genética contida no ADN (ASSAF, 2018), cujo objetivo é o de investigar doenças em nível populacional, considerando fatores genéticos e ambientais (DEPARTMENT OF HEALTH, 2015).

Nesse sentido, como a República da África do Sul possui uma das populações geneticamente mais diversas do mundo, o qual, combinado com uma alta carga de doenças e infraestrutura de qualidade, o país é propício para se realizar pesquisas em genética e genômica, sendo, por isso, muito procurado pela comunidade mundial de pesquisadores. Frente a isso, para coibir práticas inapropriadas surgiu a necessidade de compreender e proteger os interesses dos indivíduos (PEPPER et al., 2018).

Então, a Academia de Ciências da África do Sul, desenvolveu um estudo de consenso sobre as implicações éticas, legais e sociais envolvendo essas questões (ASSAF, 2018). Em adicional, também foram empreendidas iniciativas no país para tratar sobre ética em pesquisa, por exemplo, as diretrizes propostas pelo Departamento de Saúde (DEPARTMENT OF HEALTH, 2015) e o Código San de Ética em Pesquisa (SOUTH 
AFRICAN SAN INSTITUTE, 2017). Em todos esses estudos o princípio ético de respeito foi versado. Dessa forma, nota-se que a população daquele país se preocupa com o respeito, considerando-o como um elemento importante para nortear uma conduta ética.

Tendo em conta o papel da pesquisa que é a ação de fazer uma investigação sistemática com base em padrões científicos e éticos apropriados ao contexto (DEPARTMENT OF HEALTH, 2015), qualquer pesquisa que não atenda a um elemento ético que seja, é, portanto, antiética. Lembrando que, independentemente de como for e de qual seja o objetivo, o respeito sempre é um elemento apropriado em todas as situações.

Assim, dentro desse contexto, e considerando que o campo de pesquisa em genética e genômica está em constante expansão, é primordial tratar sobre as implicações éticas resultantes dessa prática. Por isso, este trabalho tem como objetivo propor o princípio ético de respeito como elemento essencial nas pesquisas envolvendo genética e genômica.

Esse princípio foi fundamentado no saber emanado pela Logosofia[2]:

Seu nome reúne numa só palavra os elementos gregos lógos e sophía, que o autor adotou, dando-lhes a significação de verbo criador ou manifestação do saber supremo, e ciência original ou sabedoria, respectivamente, para designar uma nova linha de conhecimentos, uma doutrina, um método e uma técnica que Ihe são eminentemente próprios (PECOTCHE, 2013, p. 15).

Na seção seguinte é descrito como domínios do conhecimento convergentes podem auxiliar na compreensão de temas complexos. A Seção 3 resume três estudos sobre ética realizados na África do Sul. Já a Seção 4 contém a análise e as considerações sobre essas investigações. Na Seção 5, é relatado como o princípio ético de respeito pode ser um elemento essencial em pesquisas genéticas e genômicas. $E$, na última seção é tecida a conclusão. 


\section{ESTUDOS CONVERGENTES}

Quando é necessário compreender um tema difícil, contendo conceitos de diversos domínios do saber, são feitos esforços convergentes para buscar soluções a determinados problemas; por exemplo, a bioética, a biotecnologia e o biodireito, os quais são descritos a seguir.

\subsection{BIOÉTICA}

O ramo do saber da bioética surgiu com a necessidade de estabelecer um padrão moral universal, dado o crescente interesse pela ética filosófica, além da teologia e do entrecruzamento da ética com as ciências da saúde. Logo, a bioética é um estudo transdisciplinar que engloba a biologia, a medicina, a filosofia e o direito, que, juntas, investigam condições adequadas para manter uma convivência harmônica. Em outras palavras, é uma disciplina que direciona seus esforços para compreender aspectos éticos colocados pela medicina e pela biologia, avaliando questões conflitantes com implicações na sociedade, nas relações entre os indivíduos, bem como entre eles com outras formas de vida e com o ambiente (MALUF, 2020).

Para auxiliar na avaliação dessas questões, a agenda da bioética também contempla elementos da filosofia moral como fundamento, e, a partir de adequações pertinentes, visa solucionar alguma divergência, servindo, assim, como um modelo ou uma referência para ser aplicada em projetos, cujo conjunto de princípios serão utilizados para o trabalho cotidiano (BATAGELLO, 2018).

Em bioética, a prática do bem é sempre pensada a partir de um indivíduo - visão Ocidental -, considerando as peculiaridades de cada situação, e não pensada de forma coletivizada; priorizada, por sua vez, pelo Oriente (MALUF, 2020). Mas, independentemente das visões, há um ponto em comum, o de que a bioética é a ética da vida, com princípios universais que norteiam as atividades humanas, equilibrando o progresso científico para benefício da sociedade (OLIVEIRA, 2001). 
Nessa perspectiva, na sequência são descritos os princípios fundamentais da bioética, com foco maior direcionado para a ética em pesquisa.

\subsubsection{AUTONOMIA}

Prioriza a vontade do indivíduo, ou de seu representante legal, considerando seus próprios valores morais e religiosos, reconhecendo o domínio do indivíduo sobre a própria vida, isto é, corpo e mente, bem como o respeito à intimidade. A autonomia objetiva permitir a atuação com base no conhecimento de causa e ausência de coação ou influência externa de qualquer espécie. Assim, desse princípio, urge a necessidade, por exemplo, do indivíduo consentir, ou recusar, a sua participação em pesquisas (MALUF, 2020). Nesse sentido, o respeito à pessoa reconhece que a preocupação principal deve ser a de manter a dignidade, o bem-estar e os interesses relativos à segurança dos participantes da pesquisa. Além disso, o respeito às pessoas também significa a consideração dos interesses dos pesquisadores, incluindo bem-estar e segurança, reconhecimento de autoria, propriedade intelectual e interesses profissionais (DEPARTMENT OF HEALTH, 2015).

A autonomia e dignidade, isto é, o respeito à pessoa, é um princípio que exige que os indivíduos capazes de decidir sobre suas escolhas devem ser tratados com respeito, permitindo-os exercer sua autodeterminação, ou seja, o ato de a pessoa escolher por si mesma. $E$, em relação às pessoas que não são capazes ou cuja capacidade é reduzida para deliberar por si própria, elas devem ser protegidas contra danos de escolhas irresponsáveis. Em outras palavras, o respeito às pessoas inclui a obrigação moral de respeitar a autonomia, bem como a de proteger aqueles com autonomia em desenvolvimento, prejudicada ou reduzida (DEPARTMENT OF HEALTH, 2015).

Como os interesses dos participantes devem superar os interesses da ciência e da sociedade, como efeito, o envolvimento de pessoas, ou de grupos específicos, deve ser justificado na proposta da pesquisa (DEPARTMENT OF HEALTH, 2015). 


\subsubsection{BENEFICÊNCIA E NÃO-MALEFICÊNCIA}

A beneficência busca o bem-estar do indivíduo, evitando quaisquer danos, não fazendo o mal e não cometendo injustiças; deve ser uma ação praticada em prol do indivíduo, maximizando os benefícios e minimizando os possíveis riscos (MALUF, 2020). Por isso, os riscos de danos que possam resultar da pesquisa devem ser razoáveis frente ao potencial benefício, contando com uma concepção sólida e pesquisadores competentes, além de procurar melhorar a condição humana, caso contrário, é provável que não seja ético. O benefício proíbe a inflição intencional de danos ao indivíduo, isto é, não-maleficência (DEPARTMENT OF HEALTH, 2015).

\subsubsection{JUSTIÇA}

A tomada de decisão deve ser imparcial, evitando possíveis discriminações de qualquer ordem (MALUF, 2020). No sentido de justiça distributiva, visa promover a igualdade, equilibrando de forma justa o risco e o benefício entre todos os envolvidos na pesquisa. Assim, nenhum segmento da população deve ser sobrecarregado indevidamente pelos seus potenciais danos ou negar os benefícios do conhecimento alcançado. Em adicional, deve-se haver uma probabilidade razoável de a população participante se beneficiar dos resultados, sejam eles a curto ou longo prazo (DEPARTMENT OF HEALTH, 2015).

\subsection{BIOTECNOLOGIA}

A aplicação da tecnologia na biologia deu origem a biotecnologia, que, por meio de processos biológicos, pode produzir materiais e novas substâncias, ou criar e modificar organismos vivos (MALUF, 2020). Por exemplo, nos laboratórios de biotecnologia são realizadas pesquisas para manipular animais, ampliando sua resistência, tornando-os mais fortes, mais produtivos, melhores reprodutores; bactérias para auxiliar na sobrevivência ou na falência de outras espécies vegetais; e vegetais, tornando-os mais resistentes (OLIVEIRA, 2001). 
O que torna isso possível, é a tecnologia de edição genética, a qual muda o ADN de um organismo por meio de processos de edição, remoção ou alteração dos genes. Já a modificação genética se refere ao processo de se introduzir um ADN estranho a um outro organismo, isto é, transgênese (PILLAY; THALDAR, 2018). Por exemplo, no caso dos alimentos transgênicos, ou seja, produzidos pelo processo de alteração e combinação de genes de outras espécies, os quais são incorporados à nova espécie, podem tornar as plantas ou os frutos mais duráveis, mais resistentes às pragas e às doenças. Um outro exemplo sobre a modificação genética em animais, é o de utilizálos para fins de transplantar seus órgãos destinados aos seres humanos (OLIVEIRA, 2001).

Nesse sentido, para haver uma forma de prevenção frente às inúmeras possibilidades abertas pela biotecnologia, surgiu a biossegurança, cujo fundamento básico é o de estudar, entender e tomar medidas adequadas para evitar efeitos indesejados ou abusivos com a sua aplicação, priorizando proteger os seres humanos, os animais e o meio ambiente (MALUF, 2020), tal como as implicações éticas para os casos onde há modificação genética nas células (DEPARTMENT OF HEALTH, 2015).

\subsection{BIODIREITO}

O biodireito é o ramo de investigação jurídica que estuda a relação dos avanços tecnológicos, na área da medicina e da biotecnologia, visando a regulamentação jurídica de questões colocadas pela bioética, além de buscar o limiar entre o respeito à liberdade individual com a coibição de abusos contra outros indivíduos. Além dos princípios da bioética, outros podem ser aplicados ao biodireito, por exemplo (MALUF, 2020):

- Sacralidade e dignidade da vida: proteger a vida do indivíduo, seja pelas atividades exercidas pelos médicos e cientistas, ou pelas práticas associadas com a biotecnologia;

- Precaução: precaver contra práticas médicas e biotecnológicas que possam resultar em danos aos seres humanos, às outras espécies de vida ou ao meio ambiente. Nesse sentido, é impraticável a realização de pesquisa científica 
enquanto não se prove a inexistência de consequências maléficas, sejam diretas ou indiretas. Assim, cabe ao interessado na atividade provar a ausência de risco;

- Cooperação entre os povos: promover o livre intercâmbio de experiências científicas e de mútuo auxílio tecnológico e financeiro entre os países, mantendo sempre em vista a preservação de todas as formas de vida e do meio ambiente;

- Ubiquidade: proteger a biodiversidade, o meio ambiente, bem como o patrimônio genético, devendo, portanto, considerá-los quando houver a intenção de introduzir uma nova política legislativa.

Em suma, o biodireito se ocupa em criar dispositivos para se fazer cumprir, por meio de lei, os princípios da bioética (OLIVEIRA, 2001).

\section{ESTUDOS ÉTICOS REALIZADOS NA REPÚBLICA DA ÁFRICA DO SUL}

Alguns dos esforços para se construir princípios éticos para orientar o comportamento em situações onde há a necessidade de harmonizar divergências, tem sido, mais formalmente, a bioética. No entanto, também há pesquisas independentes nesse sentido, além de proposições encabeçada por iniciativas governamentais ou por instituições, conforme exemplificadas nas próximas subseções.

\subsection{DIRETRIZES ÉTICAS PARA PESQUISA EM SAÚDE}

Em 2015, o Departamento de Saúde da África do Sul publicou um conjunto de diretrizes, contendo princípios, processos e estruturas para orientar eticamente as pesquisas em saúde, as quais devem refletir valores de respeito, mérito científico e integridade, justiça e beneficência. Desse modo, as principais normas e padrões éticos tratados no estudo são relatados a seguir (DEPARTMENT OF HEALTH, 2015): 
- Relevância e valor: a pesquisa precisa ser relevante e estar de acordo com as necessidades do povo. Por esse motivo, a proposta deve explicar a contribuição esperada, podendo ser pela geração de conhecimento ou como forma de tornar os resultados em produtos, intervenções, processos ou serviços que possam melhorar o padrão de vida e o bem-estar;

- Integridade científica: o projeto e a metodologia da pesquisa devem ser sólidos, pois assim, provavelmente, os resultados podem ser mais confiáveis e válidos. Um projeto pobre e métodos inadequados podem resultar em danos aos participantes e efeitos com pouco ou sem nenhum benefício;

- Relação entre riscos e benefícios: antes da realização da pesquisa deve-se haver uma análise dos riscos e dos benefícios. Uma relação desejável é aquela em que o potencial risco de dano a um participante seja compensado pela probabilidade de benefício para os participantes ou para a sociedade. Em outros termos, os benefícios devem superar os riscos previstos. Não obstante, vale destacar que nenhum indivíduo deve ser exposto a riscos inaceitáveis baseado na probabilidade de benefícios alcançados pela pesquisa;

- Competência e conhecimento especializado dos pesquisadores: os profissionais devem ser qualificados e possuírem competências técnicas sobre a pesquisa a qual pretendem desenvolver;

- Engajamento dos participantes: se refere ao esforço em promover iniciativas para conscientizar os participantes e, incluindo, mas não se limitando, às comunidades. O engajamento deve ocorrer em várias etapas, tanto no planejamento da pesquisa, como durante a sua execução;

- Seleção justa dos participantes: a escolha ou exclusão devem ser justas e equitativas, fundamentada em princípios científicos e éticos sólidos;

- Respeito contínuo aos participantes: o indivíduo participante da pesquisa tem direito à privacidade e confidencialidade, incumbido aos pesquisadores garantir a adoção de medidas apropriadas para evitar a divulgação de informações que possam identificá-lo. Por isso, é importante controlar quem poderá ter acesso, tanto aos seus registros pessoais, quanto clínicos de saúde. Em outras palavras, os pesquisadores devem garantir a privacidade e a confidencialidade 
(não identificar o participante) durante toda a pesquisa, inclusive na divulgação dos resultados;

- Consentimento livre e esclarecido: a participação na pesquisa deve ser voluntária, em que a pessoa decide livremente após ter tido contato com informações relevantes para conhecimento e compreensão, bem como entender o seu objetivo e quais os potenciais riscos. O direito a escolha livre é negado quando há coerção, ou seja, ameaça direta de sanção negativa ou por influência indevida. Além disso, durante a pesquisa, deve-se ocorrer um processo de consentimento contínuo para permitir a desistência do participante em qualquer momento que desejar.

Há diferentes formas de consentimentos que podem ser aplicados, a depender da abrangência da pesquisa. Por exemplo, o consentimento restrito é aquele em que o doador permite o uso dos dados ou das amostras biológicas apenas uma vez, não sendo possível o armazenamento do restante da coleta, isto é, o excedente não utilizado. Além disso, não é permitido o seu compartilhamento ou aplicação para outra finalidade; caso uma nova pesquisa seja proposta, é preciso uma nova aprovação.

O consentimento escalonado é quando o indivíduo aceita participar da pesquisa atual e decide sobre a possibilidade de compartilhamento dos dados e das amostras biológicas, bem como posteriores usos.

Já o consentimento amplo é adotado quando o doador concorda em participar da pesquisa e permite $o$ armazenamento de suas informações para trabalhos futuros, porém, para isso, a sua natureza precisa estar descrita da forma mais completa possível e estipular sobre a necessidade de uma revisão ética prévia antes da realização da nova pesquisa. Também pode-se solicitar permissão para contatos subsequentes com o doador caso o uso futuro não tenha sido contemplado no escopo do consentimento original, ou ainda para tratar sobre outras questões. 


\subsection{ESTUDO DE CONSENSO SOBRE AS IMPLICAÇÕES ÉTICAS, LEGAIS E SOCIAIS EM GENÉTICA E GENÔMICA}

A Academia de Ciências da África do Sul - Academy of Science of South Africa (ASSAf) -, em 2016, se comprometeu em realizar um estudo de consenso acerca das implicações éticas, legais e sociais no contexto de trabalhos relacionados a genética e genômica, por estarem ligados a prestação de serviços de saúde e em aplicações forenses (médicas e legais) daquele país. Nesse sentido, o estudo teve como objetivo fornecer um conjunto de recomendações contendo uma combinação das práticas empregadas por outros países, porém, adaptadas às condições da África do Sul, para auxiliar os departamentos de Saúde, Ciência e Tecnologia e outros departamentos relevantes a elaborarem políticas, bem como redigir legislação, regulamentos e orientações. O relatório possui três áreas temáticas, sendo a primeira abordando a construção de relacionamentos, depois são contemplados aspectos associados ao respeito às pessoas, e, por último, como fazer uma boa gestão. Todas as recomendações são voltadas para promover o diálogo e o intercâmbio de ideias (PEPPER et al., 2018).

Na prestação de serviços em saúde na África do Sul, são considerados os valores do Batho Pele, "significando pessoas primeiro[3]" (ASSAF, 2018, p. 26; tradução do autor), alicerçados nos valores morais de respeito às pessoas, veracidade, cortesia, reparação, abertura e transparência; e, alguns exemplos dos seus princípios são: consultoria, padrões de serviço, acesso, informação, valor para o dinheiro, encorajar a inovação e recompensar a excelência. Devido a ênfase em relações respeitosas, é fundamental o envolvimento genuíno e efetivo da comunidade como sendo essencial para os serviços de saúde, bem como para as pesquisas em genética e genômica (ASSAF, 2018).

O estudo de consenso analisa as pesquisas sob a perspectiva da filosofia Ubuntu, podendo ser traduzida como "eu sou porque somos[4]" (PEPPER et al., 2018, p. 1; tradução do autor). Para essa filosofia, no cenário africano, "o eu só faz sentido em relação à comunidade[5]" (ASSAF, 2018, p. 17; tradução do autor). Dessa maneira, a 
sua aplicação, em termos de reciprocidade, é refletida em questões sobre a forma de realizar a pesquisa, quem a conduz e como são afetados os participantes e suas comunidades, já que a pesquisa deve melhorar a vida e o bem-estar dos seus membros; por exemplo, utilizando os seus resultados para influenciar a política de saúde, fornecendo cuidados auxiliares aos integrantes da comunidade ou promovendo oportunidades educacionais. Essas práticas são condizentes com o conceito do Ubuntu, em que a humanidade evolui auxiliando os indivíduos a aperfeiçoar sua própria capacidade, além de possibilitar que os pesquisadores locais contribuam para suas sociedades. Embora, os conceitos de autonomia e de comunidade possam estar em tensão, esses princípios se complementam, no sentido de que todos os direitos fundamentais devem ser compreendidos dentro da matriz da comunidade. Por exemplo, no que se refere a comercialização de recursos genômicos, a filosofia Ubuntu o considera como propriedade pública, e não privada (ASSAF, 2018).

Dada uma visão geral de como os valores do Batho Pele e da filosofia Ubuntu fundamentam as políticas de saúde da África do Sul, na sequência são apresentados alguns aspectos descritos no estudo produzido pela ASSAf (2018).

\subsubsection{CONSTRUINDO RELACIONAMENTOS}

O objetivo da construção de relacionamentos é o de engajar o público, provendo informações concernente a genética e genômica, bem como a sua relação com os profissionais. O público corresponde a totalidade de muitos grupos, comunidades e pessoas que constituem uma população diversificada. A característica determinante de uma comunidade é a identificação comum entre seus membros, tal como, profissionais que atuam em uma mesma área.

Informar o público não é para fazê-los concordar com o que está sendo proposto, mas sim, promover o intercâmbio de conhecimentos, perspectivas e preferências entre grupos, que muitas vezes diferem em especialização, poder e valores, e desse modo, chegar em um consenso. 
No engajamento envolvendo os profissionais com uma comunidade diretamente impactada, devem ser abordadas questões de como planejar a pesquisa da melhor forma, qual a função a ser desempenhada pelos seus membros e como informá-los.

Durante o desenvolvimento de estratégias, deve-se considerar as particularidades de cada grupo e formar uma relação de reciprocidade entre os profissionais com as comunidades, promovendo o engajamento dos seus membros, por meio de reuniões, conselhos consultivos comunitários e implementação do princípio de pesquisa que encoraja a participação ativa. O sucesso da relação deve ser avaliado de forma objetiva e contínua pelos pesquisadores e pelas comunidades, ou pelo público.

Além de implementar medidas eficazes para melhorar o conhecimento e a compreensão do público sobre genética, genômica e tecnologias associadas, outros exemplos de recomendações para se construir bons relacionamentos são os seguinte: existir um comprometimento entre pesquisadores, financiadores, reguladores, comitês de ética e comunidades; proteger o público e responsabilizar os envolvidos para os casos em que ocorram condutas inadequadas; e manter a transparência na prática da ciência forense, bem como nos setores acadêmicos, públicos e privados.

\subsubsection{RESPEITO ÀS PESSOAS}

O respeito às pessoas é universalmente aplicável, sendo, portanto, considerado como um cuidado responsável 0 ato de informá-las caso necessitem de assistência relacionadas à saúde, mesmo que não saibam, e então o indivíduo decide aceitar, ou não, o auxílio.

A prerrogativa de decisão é assegurada pela Constituição da África do Sul, ao reconhecer e proteger o direito à dignidade, à vida, à integridade física e psicológica, incluindo segurança e controle sobre o próprio corpo, logo, legalmente e eticamente, cada indivíduo tem o direito de fazer escolhas livres e informadas.

Em uma pesquisa, tanto os participantes quanto suas comunidades precisam ser consultadas, devendo, por isso, aplicar o consentimento livre e esclarecido, constando 
as seguintes informações: se os resultados serão devolvidos; acordos de compartilhamento de benefícios; armazenamento e reutilização de dados e amostras, incluindo sua gestão; limites à retirada de dados e amostras uma vez compartilhados (ver: 3.2.3 Boa Gestão, a seguir); detalhes referentes à exportação de amostras; proteção de privacidade nos países para os quais os dados e amostras são exportados; as circunstâncias específicas que limitam a confidencialidade sobre os dados de ADN.

As amostras de ADN não podem ser totalmente anônimas, porque é necessário poder reidentificá-las. A justificativa é a de que o anonimato não permitiria contatar a pessoa para possíveis intervenções, por exemplo, sobre uma descoberta que poderia influenciar a sua saúde ou alterar o curso de uma doença. Para essa situação, devese haver uma política para orientar as decisões sobre a forma de divulgar descobertas incidentais. Por outro lado, a reidentificação de um participante possibilita que mais informações pessoais sejam reveladas, afetando assim, a confidencialidade.

Além disso, também é necessário informar ao participante sobre o uso potencial das informações resultantes da pesquisa e possíveis descobertas inesperadas, porque mesmo que uma determinada variante genética não esteja compreendida na pesquisa ou na intervenção clínica, no momento da análise, pode ser descoberto algum distúrbio genético; por isso, é necessário constar um acordado sobre a permissão para compartilhar os resultados com os parentes de sangue.

Em outros termos, para que seja possível a partilha dos resultados dos testes genéticos com os membros da família, é imprescindível o consentimento do participante, o qual precisa permitir o compartilhamento, assim como a reutilização, bem como dentro de uma relação de reciprocidade, isto é, devendo promover o bemestar dos indivíduos e da comunidade que doaram as amostras. Isso é necessário porque é uma forma de compartilhar os benefícios obtidos com a pesquisa, além de evitar possíveis exploração de alguma comunidade.

Por outro lado, as políticas de partilha de dados devem equilibrar os benefícios científicos com as obrigações éticas para com os participantes. Isto significa que para 
haver uma atitude de respeito às pessoas, é necessário manter os interesses e os direitos, tanto do indivíduo quanto do coletivo, especificamente ao que se refere à autonomia, privacidade, confidencialidade e acesso aos benefícios decorrentes dos resultados da pesquisa, reconhecidos e protegidos de maneira equilibrada, razoável e justificável.

Os materiais biológicos humanos coletados são armazenados a longo prazo em repositórios chamados de biobancos, nos quais ficam as coleções organizadas para serem distribuídas para fins de pesquisas, e, por conseguinte, podendo ocorrer alguma descoberta anos depois de o material genético ter sido coletado. Por isso, é importante uma interação contínua para realizar posteriores interrogações sobre evidências que possam vir a surgir, as quais não fizeram parte do consentimento original, ou para validar usos posteriores de suas amostras.

Devido a esses repositórios conterem registros médicos, o acesso às informações necessitam de políticas eficazes ou de autorização por escrito do participante, de forma a equilibrar os direitos de privacidade com outros interesses concorrentes, porque dada a natureza das pesquisas genéticas e genômicas, em que há uma ampla gama de interessados em realizar investigações que requeiram acesso aos registros de saúde, a privacidade é mantida tanto quanto possível, portanto, isto deve ser informado aos participantes como parte do processo de consentimento.

A privacidade é um direito previsto em lei, em razão disso, é uma obrigação legal a que têm os pacientes e participantes da pesquisa. Nesse sentido, o cenário jurídico da África do Sul exige um equilíbrio entre proteção de informações pessoais e o direito de acesso às informações pessoais e o direito à liberdade de expressão. Ou seja, a coleta de uma amostra genética de um indivíduo, os próprios testes genéticos, o conhecimento obtido com a análise, bem como a divulgação ou publicação dos resultados sem o consentimento da pessoa é uma violação do direito à privacidade em termos de lei comum e do direito constitucional à privacidade.

Quando a pesquisa for concluída, é uma boa prática relatar os resultados aos participantes e às suas comunidades, no entanto, é importante destacar que os 
pesquisadores não podem relatar seus resultados de maneira que possam ser, ou que possam ser percebidos, como prejudiciais ou ofensivos.

\subsubsection{BOA GESTÃO}

A gestão é a atuação cuidadosa para com a sociedade, em que os profissionais devem atuar de acordo com os interesses do povo, visando o benefício de todos. Assim, no contexto de pesquisa em genética e genômica, uma boa gestão pretende enfatizar características de integridade, honestidade, responsabilidade, compartilhamento e colegialidade, isto é, tomada de decisão consensual.

A estrutura de gestão tem como objetivo geral assegurar que os recursos genômicos sejam gerenciados com cuidado, responsabilidade e sustentabilidade. Além disso, para que sua estrutura seja confiável, é necessário que haja transparência das expectativas e dos processos, bem como consistência na execução dos requisitos.

Um pressuposto fundamental para a estrutura é concernente aos processos e procedimentos, os quais devem ser baseados em integridade, honestidade, responsabilidade, prestação de contas e eficiência. Já a concepção da estrutura precisa ser articulada sobre os valores éticos de justiça, equidade, proteção dos interesses dos doadores e explicar como será feito a promoção desses valores.

Os recursos genômicos precisam ser vistos como um bem comum, implicando que o uso ou posse não deve levar a ganhos financeiros ou outras formas de ganhos para os indivíduos. Por outro lado, é reconhecido que para realizar tais projetos é necessário financiamento e que algum ganho monetário é inevitável. No entanto, idealmente, os resultados com pesquisas ou inovações devem beneficiar todos os seres humanos, ou seja, toda a população do Globo, especialmente a população do país que contribuiu com as informações genéticas. De outro modo, é necessário que o benefício seja apropriadamente distribuído, não apenas entre as entidades públicas e/ou privadas que desenvolveram o projeto, mas também ao grupo ou comunidade que contribuíram com o material genético. 
Sendo assim, é necessário prestar contas aos doadores no decorrer da pesquisa, desde a coleta até a gestão das amostras, bem como para o uso secundário, isto é, destinado para outros fins, distintos ao da pesquisa original.

Uma estrutura de boa gestão, no que diz respeito a trabalho genômico na África do Sul, deve ser responsável e possuir comprovação sobre o valor social gerado pelo compartilhamento para evitar explorações a quem doou as amostras biológicas. Nesse sentido, os promotores de alguma iniciativa precisam demonstrar que a população da África do Sul será a beneficiária com a pesquisa, e não apenas indivíduos, empresas ou colaboradores estrangeiros em particular.

A partilha do material genético tem o potencial de promover a eficiência operacional, porque os custos são reduzidos ao se evitar coletas repetitivas de amostras, bem como atenuar a carga sobre os participantes ou pacientes ao não precisar realizar novos procedimentos e eventos que envolvam consentimentos. Além disso, o compartilhamento pode contribuir para a promoção da justiça, uma vez que outros pesquisadores podem ter acesso aos recursos, e assim, evita-se a concentração do financiamento e dos esforços de pesquisa ante um número limitado de laboratórios e equipes de pesquisas.

No entanto, uma visão de contraposto é a de que a partilha dos recursos genéticos levanta questões relacionadas a proteção da privacidade e de possibilidades de danos aos doadores (abordado na Seção 4). Por esse motivo, o compartilhamento necessita ser regulamentado por comitês para que analisem os pedidos de acesso, devendo, para isso, contar com uma equipe multidisciplinar, cujos membros precisam possuir experiências em pesquisas genômicas ou biobancos, especialistas jurídicos, cientistas, profissionais de bioinformática e eticistas, isto é, profissionais especializados em ética.

Os trabalhos na área de genética e genômica devem seguir altos padrões de qualidade éticas, e, caso não existam, é necessário criá-los para haver boas normas de condutas e, quando necessário, ter uma estrutura apropriada e legal para responsabilizar os profissionais sempre que atuarem de maneira antiética. 
Embora seja conhecido que condutas erradas devem ser sancionadas, uma estrutura proativa, enfatizando o treinamento em gestão e educação ética pode promover comportamentos adequados e que facilite a manutenção de um ambiente clínico saudável, além de um ambiente de pesquisa livre de medo, parcialidade, influência indevida e corrupção. Por isso que o teor da estrutura deve ser essencialmente proativo, e não reativo.

Com relação a gestão dos biobancos, há um agravante quanto ao direito de o participante retirar o seu registro médico, porque tais informações já podem ter sido distribuídas, processadas, transformadas e trocadas entre vários outros repositórios. Devido a isso, os participantes precisam ser informados sobre essa questão problemática.

\subsubsection{RECOMENDAÇÕES GERAIS}

Todas as recomendações são no sentido de orientar a concepção de políticas para redigir legislação, regulamentos e diretrizes ou normas para regulamentar o campo da genética, da genômica e das áreas associadas na África do Sul. Durante o processo de elaboração de políticas, deve-se haver o engajamento do público e das comunidades, contando com ações éticas, apoiadas em bases legais, além de considerar questões culturais, que sejam viáveis, exequíveis e sustentáveis.

Também deve existir uma supervisão, exercida por um órgão para intermediar implicações éticas complexas, consideradas problemáticas pelos comitês de ética em pesquisa, pesquisadores, pacientes ou participantes, ou ainda pelo público em geral. Além disso, é necessário outro órgão para tratar das implicações jurídicas e criar uma estrutura para o descumprimento da legislação, aplicando sanções eficazes.

Em suma, as recomendações gerais são as seguintes: na área temática sobre construção de relacionamentos, recomenda-se engajar os profissionais, a comunidade e o público, com atenção especial às partes interessadas; promover a educação e a tradução da ciência em política e prática, contando com avaliação regular; propor meios para que o público entenda o seu papel sobre a participação 
nos projetos de pesquisa, além de estarem cientes de suas responsabilidades e direitos; criar regulamentações para comercializar e realizar testes genéticos. A segunda área temática, de respeito às pessoas, objetiva alinhar as estruturas legal e ética com a proteção de informações pessoais, acesso, controle e uso de informações e dados pessoais, além de recomendar a criação de um consentimento livre e esclarecido que contenham todas as considerações essenciais. A última temática é sobre a boa gestão, recomendando que deve haver o compartilhamento equitativo $e$ responsável, alinhado com as políticas e diretrizes internacionais; promover o diálogo sobre a propriedade ou custódia de material biológico, uso secundário, testes, partilha de benefícios e propriedade intelectual; estabelecer um conselho para orientar os formuladores de políticas e estruturas reguladoras, além de supervisionarem os trabalhos sobre genética e genômica, bem como oferecer capacitação a esses profissionais; desenvolver análises técnicas, científicas, computacionais, bioinformáticas e estatísticas, contando com conhecimentos financeiros, legais e éticos; criar uma estrutura com expectativas claras de como se evitar danos ou ofensas ao relatar resultados de pesquisa; elaborar um código de conduta para os profissionais e criar mecanismos para sancionar quem não cumprir as exigências (PEPPER et al., 2018).

\subsection{CÓDIGO SAN DE ÉTICA EM PESQUISA}

A comunidade indígena San vive na África Austral, principalmente na África do Sul, Botsuana e Namíbia, além de habitarem, em pequenas populações remanescentes, a Angola, a Zâmbia e o Zimbábue. Como medida para controlar as pesquisas realizadas nessas comunidades, a instituição WIMSA (Working Group of Indigenous Minorities in Southern Africa), financiada por instituições da Suécia e da Holanda, criaram, em 1998, um formulário de aprovação de ética, exigindo o seu preenchimento com informações sobre o projeto antes de os pesquisadores adentrarem na comunidade. E, em 2017, duas organizações, SASI (South African San Institute) e SASC (South African San Council), em parceria com o TRUST Project[6], financiado pela União Europeia, introduziram um documento, chamado Código San de Ética em Pesquisa, para orientar os pesquisadores que queiram realizar trabalhos nas 
comunidades San a cumprirem certas exigências (SCHROEDER et al., 2019), como as descritas nos princípios a seguir (SOUTH AFRICAN SAN INSTITUTE, 2017):

- Respeito aos indivíduos, à comunidade, à cultura, à história, a proteção permanente da privacidade; incluindo a relação dos San com o ambiente, o reconhecimento pela contribuição, o cumprimento das promessas e a colaboração dos pesquisadores para com a comunidade;

- Honestidade dos pesquisadores; partilha de informações aberta, clara e honesta, contendo uma avaliação prévia dos possíveis prejuízos ou problemas resultantes da pesquisa aos San; apresentação de um consentimento livre e esclarecido; transparência em todos os aspectos, incluindo a situação de financiamento, o objetivo da pesquisa e quaisquer alterações que possam ocorrer durante o processo; comunicação aberta e contínua entre os San e os pesquisadores;

- Justiça e imparcialidade; participação ativa dos San nas pesquisas propostas, incluindo o conhecimento dos respectivos benefícios; aplicação de sanções no caso de infração ao Código San;

- Cuidados com as comunidades locais e a todas as pessoas envolvidas, abrangendo atenção às famílias e ao ambiente social e físico; realizar uma pesquisa de qualidade que possa ser positiva e atenciosa para com os San; aceitar o povo San tal como é, considerando as necessidades culturais e sociais:

- Processo cuidadoso, isto é, os pesquisadores devem seguir os processos estabelecidos nos protocolos de pesquisa, que será gerido pelo Conselho dos San. O processo se inicia com uma ideia de pesquisa, a qual deve ser definida em conjunto até a aprovação do projeto e posterior publicação.

\section{ANÁLISE E CONSIDERAÇÕES SOBRE OS ESTUDOS ÉTICOS}

A bioética, como sendo a ética da vida, tem como foco manter a harmonia entre todas as formas de vida e entre elas com o meio ambiente. Para isso, dispõe de princípios como: autonomia, a qual preconiza a dignidade, o respeito ao indivíduo, permitindo que escolha de forma livre e com conhecimento de causa; beneficência, buscando 
maximizar o bem e minimizar os danos, além de proibir a prática intencional de danos; e justiça, que visa a imparcialidade e a distribuição equilibrada. Já a biotecnologia é a busca para produzir materiais e substâncias a partir de processos biológicos, bem como alterar ou manipular os genes dos seres vivos. E, o biodireito, focado em criar legislação para proteger todas as formas de vida e o meio ambiente frente as novas tecnologias produzidas com as biotecnologias, como também pelos dilemas colocados pela bioética.

Com relação aos princípios fundamentais da bioética, Oliveira (2001), argumenta que se houver descumprimento de algum dos seus princípios, é necessário refletir e decidir com base no valor fundamental de maior hierarquia, que é a dignidade humana. Por sua vez, Batagello (2018), relata sobre a necessidade de se construir uma nova teoria ética que incorpore os conhecimentos alcançados pelas ciências médicas e da vida, no que se refere ao comportamento do ser humano.

É vital presar pelos valores fundamentais para todos os indivíduos, e, em nenhuma circunstância relativizá-los para atender a certos interesses. Por exemplo, o fato de a ciência ter alcançado o potencial de clonar um ser humano, não significa que deva fazê-lo; essa negação inclui, inclusive, mesmo que a maioria das pessoas passem a considerá-la uma prática aceitável.

A relativização ou o relaxamento dos valores morais que cada pessoa cultiva em si, se refletido na prática da ciência, acarretará pesquisas obscuras, onde os esforços serão empenhados para atender a interesse específicos, ignorando o bem comum e a melhoria do bem-estar para a sociedade como um todo.

Quando os cientistas trabalham em experimentos e procedimentos alheios aos valores éticos e morais, Oliveira (2001, p. 36), escreve:

Envolvidos sobretudo no progresso da ciência, muitas vezes os experimentos são desenvolvidos sem discutir qualquer valoração: o ético e o moral são deixados de lado para chegar-se ao final da pesquisa, sem o que ela se tomaria inviável. É o tudo vale em nome da Ciência. É o tudo vale em nome do avanço tecnológico. Como se este fim justificasse 
o rompimento com todos os atuais valores morais e éticos existentes em cada um e vigentes na sociedade.

Frente a essa problemática, o Departamento de Saúde da África do Sul redigiu um conjunto de diretrizes para orientar pesquisas em saúde, cujas principais normas e padrões para a condução de pesquisas com ética são as seguintes: a pesquisa deve ser relevante, que possibilite melhorar o padrão de vida e o bem-estar; o projeto e a metodologia devem ser sólidos e robustos; os riscos e os benefícios devem ser cuidadosamente avaliados; os pesquisadores devem ser competentes e possuir conhecimento especializado sobre a pesquisa que pretende realizar; os participantes devem ser encorajados a se engajarem com a pesquisa, selecionando-os de forma justa, mantendo o respeito para com eles durante toda a pesquisa, assim como na divulgação dos resultados, bem como aplicar o consentimento livre e esclarecido (DEPARTMENT OF HEALTH, 2015).

Considerando que as pesquisas precisam contribuir para elevar o padrão de vida e proporcionar bem-estar, a sua execução deve ser condicionada a fatores, tais como, além de avaliar criteriosamente sobre os riscos e os benefícios, também considerar como fator determinante o respeito ao indivíduo. Por exemplo, se a pesquisa envolver risco a um participante, mesmo que o potencial benefício possa superar o possível risco, a pesquisa não pode prosseguir enquanto o procedimento a ser testado não se prove eficaz, isto é, que se produza o efeito esperado, sem consequências colaterais. Caso contrário, os pesquisadores precisam encontrar soluções alternativas.

Com relação a regulamentação das pesquisas que envolvem seres humanos, vale destacar o que foi apontado por Oliveira (2001), em que é necessário considerar, em primeiro lugar, o anseio da sociedade para não incorrer no erro de as legislações atenderem exclusivamente aos interesses de obtenção de lucros para as empresas que desenvolvem biotecnologias. As regulamentações precisam ser validadas pelos membros da sociedade, e, para isso, é preciso uma ampla divulgação para informar e esclarecer do que se trata a pesquisa, para que se possa saber o seu real objetivo, quais são os riscos e os benefícios resultantes. 
As legislações precisam atender aos interesses da coletividade embasada em valores fundamentais para os seres humanos a fim de que as normas jurídicas não sirvam aos interesses do mais forte; também conhecido como biopoder. À vista disso, o biodireito pode ser a base da prática jurídica. No entanto, para isso, não pode haver intervenção externas das empresas ou dos laboratórios, porque o conjunto de leis deve proteger os indivíduos e não as organizações. Em outras palavras, é preciso cautela na busca pela regulamentação para não permitir que os detentores do biopoder transformem seus interesses em lei, excluindo assim, a vontade da coletividade; portanto, cabe a sociedade exigir segurança no sentido de não permitir a consolidação do biopoder (OLIVEIRA, 2001).

Por exemplo, o objetivo do TRUST Project foi o de encontrar maneiras para controlar pesquisas indesejadas (SCHROEDER et al., 2019). Sendo assim, vale perguntar: A quem ou para quais grupos as pesquisas poderiam ser indesejadas? Esse é um caso em que o biopoder poderia ditar as regras, impondo seus próprios interesses ao limitar ou impedir a realização de pesquisas que de alguma forma os prejudicariam.

A ciência deve servir a propósitos de bem, isto é, a de desenvolver conhecimento e tecnologia em benefício de toda a sociedade. Mas, como indaga Archer (1992), caso a liberdade dos cientistas seja ameaçada e a ciência fique subordinada aos interesses do mercado, do poder econômico ou do poder político, é possível que a ciência cumpra o seu objetivo de servir ao interesse geral da sociedade?

A respeito das implicações éticas da biotecnologia, Archer (1992), observa que o desenvolvimento da biologia seguiu uma linha mecanicista, desconsiderando "muitos dos mistérios da vida a mecanismos químicos" (ARCHER, 1992, p. 143), e que o sequenciamento do genoma acentuou essa tendência, além de reduzir a vida humana e sua natureza, fazendo-nos esquecer da dimensão espiritual e ética do homem.

O olhar mecanicista da biologia e o esquecimento espiritual, quando refletido na ciência, criam-se situações e pesquisas que podem levar a dilemas éticos complicados. Por exemplo, Oliveira (2001) salienta que, com o desenvolvimento de projetos envolvendo engenharia genética, criou-se promessas para a cura das mais 
variadas doenças, no entanto, como se encontram as questões sob uma análise ética em sua elaboração? A autora ainda pergunta:

Todas adotam ou possuem critérios previstos a serem rigorosamente obedecidos durante o desenvolvimento dos trabalhos? Os fins a serem alcançados por estas e outras pesquisas sempre são os de buscar o bem, a saúde, o alimento, entre outros, para todos os seres humanos? (OLIVEIRA, 2001, pp. 18-19).

As pesquisas em genética e genômica tem como objetivo compreender a base molecular de uma doença para que seja possível aplicar uma abordagem baseada em provas. No entanto, a identificação dos genes que podem estar relacionados com uma determinada doença requer o conhecimento sobre outras doenças que podem influenciar o quadro clínico geral do paciente, portanto, o valor preditivo de doenças é muito baixo (ASSAF, 2018).

Somado ao baixo valor preditivo em decorrência de outras doenças que podem interferir no estado de saúde, o potencial de combinações genéticas é ilimitado, consequentemente, cada ser humano possui uma sequência de ADN única, com exceção de quando nascem gêmeos idênticos (ASSAF, 2018). Ou seja, a existência de inúmeras sequências genéticas, somado a outros fatores que influenciam na composição biológica no todo do indivíduo, geram desafios únicos. Até mesmo nos casos de gêmeos idênticos haverá influências diversas, porque, ao longo de suas vidas, cada um terá as suas próprias experiências, frequentarão ambientes distintos, se alimentarão de forma diferente, dentre outros fatores.

Se tratando de ética em pesquisa genética, o Departamento de Saúde da África do Sul alerta sobre pontos a serem considerados, com especial atenção às propostas de pesquisa, as quais devem constar o seu valor social, o consentimento, a privacidade, a confidencialidade, bem como o efeito potencial da pesquisa sobre as famílias, comunidades e outros grupos. Além do mais, a proposta precisa incluir um plano contendo a forma de como as informações encontradas na pesquisa genética serão gerenciadas. Isso deve ser informado aos participantes para que eles decidam se gostariam de receber informações pessoais e se poderiam ser compartilhadas com parentes biológicos. Caso optem por receber tais informações, é importante haver um 
aconselhamento aos participantes sobre as questões genéticas (DEPARTMENT OF HEALTH, 2015).

A Academia de Ciências da África do Sul, considera que é uma atitude respeitosa manter o direito de a pessoa decidir livremente sobre a sua participação em pesquisas. Assim, é preciso o consentimento de todos os participantes, do início até a publicação dos resultados, caso contrário há uma violação de privacidade (ASSAF, 2018). Sobre a privacidade genética, Oliveira (2001), pronuncia que é um direito fundamental e inviolável dos seres humanos, e, por isso, deve ser respeitado, com exceção de quando o próprio interessado renunciar o direito à privacidade de forma livre e espontânea.

No estudo da Assaf (2018), é exposto uma contradição ética no que diz respeito a doação de amostras biológicas, em que, por um lado, é desencorajado ou até mesmo chega-se a proibir a remuneração pelas amostras biológicas, porém, por outro lado, é permitido, ou até mesmo incentivado, a comercialização de dados obtidos a partir das amostras. Ou seja, a recompensa pelo trabalho é aceita, mas, pagar pelas amostras, as quais possibilitaram a sua realização, é considerado antiético.

Frente a isso, é necessário criar meios para compartilhar os benefícios, já que é um contrassenso permitir a geração de riquezas de um lado, sem a devida contrapartida para quem doou o material genético. Em outros termos, espera-se que quem provê amostras biológicas, o façam por uma causa nobre, como um presente com base no altruísmo, enquanto os pesquisadores ou seus empregados se beneficiam, utilizandoas com propósitos comerciais ou para construção de carreira profissional (ASSAF, 2018).

A informação genética não deve ser vista como algo a ser comercializada para atender a fins financeiros; essas informações, tão intima e única para cada indivíduo não pode ser tratada sob a ótica materialista e/ou para atingir finalidades monetárias. Por exemplo, para não ocorrer situações em que, se o indivíduo não der seu consentimento para uso secundário ou partilha de suas informações genéticas, o procedimento a que necessite seja inviabilizado. 
Portanto, a privacidade genética é comprometida quando há o compartilhamento do material genético, inclusive podendo resultar em danos aos doadores no caso onde seguradoras de saúde tenham acesso às informações genéticas dos clientes e as utilizem como forma de tabelar os preços, cobrando mais caro ou mais barato, de acordo com a probabilidade de desenvolver doenças e precisarem de certos tratamentos. Ou ainda, outra situação prejudicial é a de quando as instituições privadas de assistência previdenciária façam uso de métodos similares (OLIVEIRA, 2001). Nesse sentido, o uso irresponsável das informações genéticas por empresas de avaliação de riscos pode resultar em práticas discriminatórias (ASSAF, 2018).

Com relação ao princípio de confidencialidade, a permissibilidade de reidentificação das amostras de ADN acarreta o seu descumprimento, portanto, se as informações genéticas forem armazenadas de forma a permitir a sua identificação futura, a confidencialidade passa a ser desconsiderada.

Quando a informação genética do paciente for coletada para auxiliar em um tratamento médico específico, cuja permissão de armazenamento não tenha sido concedida por ele, é necessário o seu descarte logo após o uso.

Por fim, a seguir são listados os princípios e valores descritos neste trabalho:

- Bioética: autonomia, beneficência e justiça;

- Biodireito: além dos princípios da bioética, somam-se a sacralidade e dignidade da vida, precaução, cooperação entre os povos e ubiquidade;

- Departamento de Saúde da África do Sul: respeito, mérito científico e integridade, justiça e beneficência;

- Academia de Ciências da África do Sul: respeito às pessoas (autonomia, privacidade, confidencialidade e acesso aos benefícios de maneira equilibrada, razoável e justificável), veracidade, cortesia, reparação, abertura, transparência, consultoria, padrões de serviço, acesso, informação, valor para o dinheiro, encorajar a inovação, recompensar a excelência, integridade, honestidade, colegialidade, responsabilidade, prestação de contas, eficiência, justiça, equidade, proteção dos interesses dos doadores, compartilhamento e 
boa gestão com os recursos genômicos (com cuidado, responsabilidade e sustentabilidade);

- Código San de Ética em Pesquisa: respeito, honestidade, justiça e imparcialidade, cuidados com as pessoas e cumprimento dos processos estipulados.

Na seção a seguir é descrito como o princípio de respeito pode contribuir para realizar pesquisas genéticas e genômicas com ética.

\section{PRINCÍPIO ÉTICO DE RESPEITO EM PESQUISAS GENÉTICAS E GENÔMICAS}

Está seção será baseada no artigo intitulado: "O respeito, fator essencial da paz", publicado em setembro de 1945 na revista Logosofia, pelo autor Carlos Bernardo González Pecotche (1901-1963), fundador da Ciência Logosófica (PECOTCHE, 1980, pp. 175-176).

A sua publicação ocorreu no mesmo mês em que terminavam as hostilidades da Segunda Guerra Mundial, cujo acontecimento serviu de base para elucidar as implicações que a falta de respeito, chegado ao seu extremo, pode suceder.

Nunca se poderá negar que o respeito mútuo entre os povos e entre os homens seja o agente ou fator essencial da paz, já que, enquanto ele existe, se aplainam todos os caminhos que levam a encontrar soluções para as diferenças criadas. Ao contrário, caso deixem de ser respeitados os tratados que foram assinados em solenes cerimônias, e se violem também as normas do direito internacional, as guerras se tornam inevitáveis, pois nada há que fira mais a dignidade de uma nação, de um povo ou de um homem do que sentir que essa dignidade foi menoscabada pela falta de respeito. Quando isso ocorre, quando o respeito deixa de ser a fiança que resguarda os convênios e as considerações mútuas, começa a rachar-se a estrutura jurídica, econômica e social dos povos (PECOTCHE, 1980, p. 175).

O respeito é o agente que mantém a paz entre os homens porque, quando há respeito reciproco, as pessoas se esforçarão em encontrar soluções harmônicas, isto é, sem buscar o benefício exclusivo para si, ignorando as necessidades da outra parte. 
Assim, nesse intento, haverá mútua consideração, com cada um dos envolvidos refletindo e ponderando sobre o que pode exigir com o que deve oferecer em contrapartida. Uma conduta nesse sentido é um meio para se chegar a soluções mais justas, considerando as diferenças, as necessidades e os interesses de todos.

Chegado a uma solução em consenso, é necessário o seu cumprimento, porque, caso contrário, o rompimento do acordo firmado gerará situações adversas, em decorrência de ter ferido a dignidade de outrem.

Isso ocorre porque o respeito é o que consolida os acordos, onde o indivíduo salvaguardará o que é seu por direito, ao mesmo tempo que concederá a outra parte o que lhe corresponde. Nesse sentido, com a violação do combinado "depressa os direitos se quebram, sobrevindo a desorientação, a desconfiança e o receio" (PECOTCHE, 1980, p. 175), já que:

Não pode haver paz num povo se o respeito às leis e a suas instituições deixa de ser a garantia que ampara cada um em seus direitos e em seus valores. Daí que, quando se burla a dignidade do homem, faltando com o respeito à sua pessoa, sobrevêm as crises sociais, tão nefastas para a vida de povos e nações (PECOTCHE, 1980, p. 175).

O desrespeito em toda a sua extensão, diretamente a um outro indivíduo, ou pelas leis e instituições, é o equivalente a retirar o que é direito do outro. Dessa maneira, é uma falta contra a dignidade da pessoa negar o seu direito ou desconsiderar os seus valores, e, o oposto, ou seja, o que permitirá uma boa convivência, é agir conforme o axioma: "Respeitar para ser respeitado" (PECOTCHE, 1980, p. 176), uma vez que será respeitado os direitos e valores, ao mesmo tempo que tem os seus próprios respeitados.

Não existe uma lei que imponha o respeito, porquanto, bem se pode dizer, ele responde a uma lei natural. Em todos os tempos, o respeito constituiu o meio imprescindível que fez realizável a convivência entre os seres humanos. O homem, desde que nasce, como tudo o que se manifesta à vida no seio da Criação, deve inspirar respeito. Nada melhor se poderia fazer, portanto, para edificar a paz futura, do que conseguir que o respeito presida a todas as suas determinações, erigindo-o como algo inseparável de sua responsabilidade (PECOTCHE, 1980, p. 176). 
A atuação respeitosa não é algo que se encontra exigido em um texto de alguma legislação; o respeito é um valor que merece ser cultivado para se manter a boa convivência, por conseguinte, evita-se desavenças que tanto atrapalha a evolução humana.

O axioma: "A tolerância termina quando começa o abuso" (PECOTCHE, 2011, p. 82) traduz o provável estado de ânimo que se encontrará a pessoa que for desrespeitada, seja pela negação de seu direito ou pela desconsideração dos seus valores. Em outros termos, por ter tido a sua dignidade afetada.

Para se manter a dignidade, é fundamental cultivar o respeito para com todos. O respeito pode ser considerado como um fator de última instância para decidir sobre como proceder em situações em que há divergências. Por exemplo, quando houver uma questão ética complicada, o consenso para a tomada da decisão pode ser fundamentado no respeito, ou seja, a deliberação não pode faltar com o respeito para com nenhum ser humano. Em outras palavras, se a decisão consensual ferir a dignidade de uma pessoa, a decisão tomada não foi corretamente avaliada.

O princípio ético de respeito traz em sua essência muitos dos princípios e valores descritos neste trabalho, por exemplo: dignidade, autonomia, beneficência, justiça, cooperação, precaução, privacidade, confidencialidade, veracidade, cortesia, reparação, integridade, responsabilidade e imparcialidade.

Nesse sentido, as pesquisas envolvendo genética e genômica podem ter como fundamento o respeito como elemento essencial para validá-las, porque, se a pesquisa proposta ferir alguns dos princípios ou valores citados acima, é pouco provável que seja ética.

Exemplificado como o respeito é um princípio essencial, não apenas em trabalhos envolvendo genética e genômica, mas em pesquisas de modo geral, bem como para se manter a boa convivência entre os indivíduos, na seção seguinte é relatada a conclusão. 


\section{CONCLUSÃO}

Para sumarizar este trabalho, inicialmente houve a contextualização dos campos de estudo da bioética, da biotecnologia e do biodireito, cujas disciplinas estão relacionadas com o propósito deste trabalho. Depois, três trabalhos foram considerados como fundamentação teórica, os quais versaram sobre ética em pesquisa.

O primeiro descreveu um conjunto de diretrizes para direcionar pesquisas em saúde, elaboradas pelo Departamento de Saúde da África do Sul. O segundo, o estudo de consenso da Academia de Ciências da África do Sul, focou em propor recomendações sobre a necessidade de desenvolver diretrizes e políticas para abordar as implicações éticas, legais e sociais relacionadas a genética e genômica. $O$ terceiro sugeriu um código de ética em pesquisa para os interessados em fazer trabalhos na comunidade indígena San, em que os pesquisadores precisam seguir os processos estabelecidos.

Em seguida, os referidos estudos foram analisados, para depois, propor a consideração do princípio ético de respeito em pesquisas genéticas e genômicas, as quais não devem ser realizadas caso firam qualquer um dos princípios ou valores vinculados ao respeito para com o indivíduo.

O cultivo interno do respeito, tornando-o em um valor moral, predisporá o ânimo do indivíduo a encontrar soluções que culminem na paz; assim, empenhará seu esforço para resolver situações divergentes, sem ferir a dignidade de outrem.

\section{REFERÊNCIAS}

ARCHER, Luis. Questões Éticas e Sociais da Análise do Genoma Humano. Acta Médica Portuguesa, v. 5, p. 139-145, 1992.

ASSAF. Genética e Genômica Humana na África do Sul: Implicações éticas, legais e sociais [Human Genetics and Genomics in South Africa: Ethical, Legal and Social Implications]. África do Sul: Academy of Science of South Africa (ASSAf), 2018. http://dx.doi.org/10.17159/assaf.2018/0033. 
BATAGELLO, Rodrigo. História da bioética: Entre uma Formação Discursiva e um Campo Científico. Revista Brasileira de Bioética, v. 14, n. e21, p. 1-16, 2018. https://doi.org/10.26512/rbb.v14i0.25573.

DEPARTMENT OF HEALTH. Ética na Pesquisa em Saúde: Princípios, Processos e Estruturas [Ethics in Health Research: Principles, Processes and Structures]. 2. ed. 2015. Disponível em: https://hpca.co.za/download/doh-2015-ethics-in-healthresearch-guidelines/. Acesso em: 11 nov. 2020.

GREELY, Henry T. CRISPR teve Bebês: Edição do Genoma Germinal Humano no 'Caso He Jiankui' [CRISPR'd Babies: Human Germline Genome Editing in the 'He Jiankui Affair]. Journal of Law and the Biosciences, v. 6, n. 1, p. 111-183, Out. 2019. https://doi.org/10.1093/jlb/lsz010.

MALUF, Adriana Caldas do Rego Freitas Dabus. Curso de Bioética e Biodireito. 4. ed. São Paulo: Grupo Almedina, 2020.

OLIVEIRA, Simone Born de. Manipulação Genética e Dignidade Humana. Florianópolis, 2001. Dissertação (Programa de Pós-Graduação em Direito) Universidade Federal de Santa Catarina, 2001.

PECOTCHE, Carlos Bernardo González. Coletânea da Revista Logosofia: Tomo I. Tradução José Dalmy Silva Gama. São Paulo: Editora Logosófica, 1980. Tradução de: Coleccíon de la Revista Logosofia.

PECOTCHE, Carlos Bernardo González. Introdução ao Conhecimento Logosófico. Tradução Antônio João da Silva. 3. ed. São Paulo: Editora Logosófica, 2011. Tradução de: Introducción al Conocimiento Logosófico.

PECOTCHE, Carlos Bernardo González. Logosofia: Ciência e Método. Tradução Filiados da Fundação Logosófica do Brasil. 12. ed. São Paulo: Editora Logosófica, 2013. Tradução de: Logosofía, Ciencia y Método. 
PEPPER, Michael S. et al. Estudo de Consenso da ASSAf Sobre as Implicações Éticas, Legais e Sociais da Genética e Genômica na África do Sul [ASSAf Consensus Study on the Ethical, Legal and Social Implications of Genetics and Genomics in South Africa]. South African Journal of Science, v. 114, n. 11/12, 27 Nov. 2018. https://doi.org/10.17159/SAJS.2018/A0302.

PILLAY, S.; THALDAR, D. W. CRISPR: Desafios à Lei de Biotecnologia da África do Sul [CRISPR: Challenges to South African Biotechnology Law]. South African Journal of Bioethics and Law, v. 11, n. 2, p. 89-92, Nov. 2018. https://doi.org/10.7196/SAJBL.2018.v11i2.653.

SCHROEDER, Doris et al. O Código San de Ética em Pesquisa [The San Code of Research Ethics]. In: EQUITABLE Research Partnerships. SpringerBriefs in Research and Innovation Governance: Springer, Cham, 2019, p. 77-87. https://doi.org/10.1007/978-3-030-15745-6_7.

South African San Institute. Código San de Ética da Investigação. Global Code of Conduct. 2017. Disponível em: https://www.globalcodeofconduct.org/wpcontent/uploads/2018/07/San-Code-of-Research-Ethics-Booklet_Portuguese.pdf. Acesso em: 10 nov. 2020.

\section{APÊNDICE - REFERÊNCIAS DE NOTA DE RODAPÉ}

2. https://logosophy.info/pt/

3. No texto original, em língua inglesa: "meaning people first".

4. No texto original, em língua inglesa: "I am because we are".

5. No texto original, em língua inglesa: "the self only makes sense in relation to the community".

6. http://trust-project.eu/

Enviado: Novembro, 2020. 
Aprovado: Dezembro, 2020. 